\title{
DESVELANDO EL POEMA CINEMATOGRÁFICO: \\ UN ENCUENTRO ENTRE LA GERMANIA DE MARTIN HEIDEGGER Y LA NARRATIVA AUDIOVISUAL
}

\author{
UNVEILING THE CINEMATOGRAPHIC POEM: A ENCOUNTER \\ BETWEEN MARTIN HEIDEGGER'S GERMANIA AND THE \\ AUDIOVISUAL NARRATIVE
}

\author{
Aarón RODRIGUEZ SERRANO \\ Universitat Jaume I \\ serranoa@uji.es
}

Resumen: Nuestro trabajo parte del seminario sobre el poema Germania de Hölderlin que Heidegger impartió en 1934. Siguiendo su estructura, nos preguntaremos por la acotación de lo poético y sus posibles aplicaciones a la filosofía del arte audiovisual. Para ello, depuraremos aquellos aspectos del texto que ofrecen mayores dificultades interpretativas (Heimat, Ursprache, Gemeinschaft...) y posteriormente analizaremos las fortalezas y las dificultades de la aplicación de estos conceptos al cine. Encontraremos el mayor problema en el concepto de lengua originaria y concluiremos ofreciendo una sugerencia sobre el posible futuro del análisis textual audiovisual heideggeriano.

Palabras clave: Martin Heidegger. Germania. Análisis audiovisual. Filosofía del arte. Narrativa Audiovisual. 


\begin{abstract}
Our work is based on the seminar about the Hölderlin's Germania that Heidegger taught on 1934. Following his structure, we will look for the limits of the poetical idea and his posible applications onto the audiovisual aesthetic. For that, we will bowdlerize those aspects of the text which offer the biggest interpretative issues (Heimat, Ursprache, Gemeinschaft...), and after that, we will analyze the strenghts and difficulties on the application of this concepts to the cinema. We will find our main problema in the original lenguaje issue and we will conclude offering a suggestion about the posible future of the heideggerean textualaudiovisual anaylisis.
\end{abstract}

Keywords: Martin Heidegger. Germania. Audiovisual analyse. Philosophy of Art. Audiovisual Narrative

\title{
1. INTRODUCCIÓN
}

En febrero de 1934, apenas unos meses después de haber abandonado su puesto como rector en la Universidad de Friburgo, el filósofo Martin Heidegger inició lo que generalmente ha sido considerado como su Kehre desde la ontología existencial hacia, entre otros, el cuestionamiento de la metafísica y el diseño de una suerte de filosofía del arte. Como ya ha quedado demostrado (Rodríguez, 2006), resulta engañoso tomar la Kehre en un sentido literal como una suerte de "traición" o de "alejamiento" con respecto a los núcleos principales de la filosofía del primer Heidegger, resultando sin duda más recomendable considerarla como un diálogo, una correspondencia o una exploración posterior sobre la pregunta por el Ser.

Uno de los primeros textos de los que tenemos noticia tras el fracaso de su rectorado es el particular acercamiento al poema Germania de Hölderlin, quizá el primer paso sólido en la creación de su posterior teoría del lenguaje y, por supuesto, a su filosofía del arte, anterior incluso a su célebre conferencia a propósito de El origen de la obra de arte (Heidegger, 
1958, 1995). Sin duda, el tono triunfalista y desmesurado de su célebre “discurso del rectorado" (Heidegger, 1989) queda aquí opacado por una suerte de melancolía, de aceptación del fracaso de su proyecto político, que puede encontrarse en muchos de sus escritos personales de la época, así como en parte de su filosofía posterior. La Germania de Hölderlin, en manos de Heidegger, se convierte también en un profundo y estimulante ejercicio de aceptación de la derrota que se parapeta tras las palabras del poeta para comenzar a trabajar en la formalización filosófica de su incompatibilidad con el nacionalsocialismo del momento y sus dogmas.

Sin embargo, no queremos que nuestro presente trabajo funcione como una suerte de exculpación del "Heidegger nazi", ni tampoco pretendemos soslayar la apabullante colección de pruebas que culpan, con mayor o menos fortuna, al filósofo de colaborar con un sistema totalitario (Farías, 2009; Quesada, 2008, y muy especialmente para el trabajo que nos ocupa, Faye, 2009). Propondremos, sin embargo, algunas matizaciones a propósito del concepto de Heimat y de su conexión con la filosofía del lenguaje que, quizá, merezcan una mayor atención de la que hasta ahora se les ha ofrecido desde los estudios heideggeranos. En ningún momento pretendemos negar que Germania está debatiendo abiertamente con los dogmas principales del nacionalsocialismo, hasta el punto de reconocer explícitamente a Spengler o a Rosenberg (Heidegger, 2010: 39) como dos de sus rivales teóricos directos en la interpretación de la herencia poética y filosófica alemana (Sherrat, 2014). Del mismo modo, somos conscientes que las dos ediciones con las que hemos trabajado el texto - el tomo 39 de las Gesamtausgabe (Heidegger, 1999b) y su traducción al castellano (Heidegger, 2010) — sufrieron diferentes reescrituras por parte del Heidegger posterior a su proceso de "desnazificación", y a su “colapso" (Zusammenbruch) (Xolocotzi y Tamayo, 2012: 164-169) por lo que nos vemos obligados a guardar siempre la necesaria distancia crítica con respecto a los puntos más oscuros de su teoría.

Muy al contrario, el objetivo principal de nuestro presente trabajo es preguntarnos por la posible traslación de los principales filosofemas 
propuestos en Germania (poema, patria, lenguaje originario...) al campo concreto del análisis audiovisual y la narrativa audiovisual, dar cuenta de sus compatibilidades, sus fricciones y sus puntos de desencuentro.

\subsection{Reivindicación del objeto de estudio}

Hay, al menos, dos motivos que justifiquen la presente investigación. En primer lugar, a menudo se ha cerrado la puerta a la explotación de la filosofía del arte heideggereana en campos que no fueran el estrictamente literario debido al evidente logocentrismo del planteamiento del alemán. En sus interpretaciones más aceleradas, la verdad y el desvelamiento (alétheia) pasan directamente a estar en conexión con el lenguaje que es, aparentemente, la única puerta de acceso al Ser. Sin pretender negar que, en efecto, el lenguaje forma parte esencial de ese segundo Heidegger (Kockelmans, 1972; Mansbach, 2002), nos parece que un estudio detallado de Germania nos obliga a preguntarnos, todavía con mayor precisión, qué lenguaje y de qué manera puede sobrepasar el límite de la palabra para saltar directamente a la construcción de imágenes.

Esto nos lleva al segundo motivo que justifica este texto. Tampoco podemos negar que Heidegger forma parte de esa tradición de pensadores que, en palabras de Curt Paul Janz, no eran "hombres de ojos" (1988: 197). Hay, como veremos, varios posibles motivos para la predilección de lo poético sobre lo visual que conectan la filosofía del arte heideggeriana con otras similares - en especial, por supuesto, la kantiana- Es necesario recordar que fue Kant el que, al colocar la poesía por encima del resto de las bellas artes en su Crítica del juicio, alabó su capacidad para “elevarse, estéticamente, hacia las ideas" (Kant, 2007: 273). Esta misma idea se repetirá al principio del análisis de Germania cuando Heidegger reivindique las conexiones entre la poesía y la filosofía, entre el poetizar filosófico y el filosofar poético, muy precisamente a través de un poeta (Hölderlin) que también fue filósofo.

Hay al menos dos motivos por los que Heidegger se negó a 
operar desde el discurso audiovisual: uno filosófico y otro autobiográfico. El primero es la conexión que realizó durante toda su vida entre el cine y los aspectos más brutales de la técnica. Una gran parte de las referencias explícitas de su obra a lo cinematográfico tienen un tono de profundo desprecio. El cine de Hollywood impide que los hombres se formen (Heidegger, 2015: 378), apoya una racionalidad "desarraigada" (entwurzelt) en la que se impone el tiempo brutal del capitalismo, el tiempo del "americanismo", un tiempo en el que la técnica se utiliza como una herramienta para arrasar el planeta y someter a los individuos a ritmos de vida antinaturales. El segundo motivo fue su evidente rechazo personal por el cine, al que no sólo veía como un arma del capitalismo americano, sino, ante todo, como el caballo de batalla privilegiado de los hombres que le habían expulsado de las jerarquías del nacionalsocialismo y que, a su juicio, habían traicionado la hipotética revolución hitleriana. Dicho con mayor claridad: como bien ha demostrado la reciente publicación de los Cuadernos negros (Heidegger, 2015: 236, 354), Heidegger encontró en el cine y en las producciones de la UFA orquestadas por Goebbles (Moeller, 2001) una suerte de "bestia negra" contra la que cargar a lo largo de sus escritos y a la que culpar de esa desviación que le alejó del centro de la filosofía nazi y que, como señalábamos comenzó a topografiar en su seminario sobre Germania. Frente a un arte capaz de recuperar la pregunta por el Ser (la poesía), se erigía una técnica manipuladora encubridora (el cine, tanto alemán como americano). Siguiendo la teoría de José Luis Molinuevo (Molinuevo, 1998: 21), es factible pensar la primera parte de su producción en la Kehre como un revulsivo contra los mecanismos culturales propuestos por el III Reich después de su caída en desgracia en el interior del nazismo.

Con este contexto como telón de fondo, es lícito preguntarse qué sentido tiene recuperar algunos rasgos de la filosofía del arte heideggeriana para clarificar las herramientas del análisis fílmico. Lo más sencillo sería, sin duda, reconducir las teorías del filósofo hacia el ámbito exclusivo de lo literario y evitar así los riesgos de una sobreinterpretación o de una "torsión 
con respecto a la ortodoxia" de su legado. Sin embargo, el presente artículo responde a una necesidad establecida en la dirección contraria: el mundo del análisis fílmico lleva décadas intentando aproximarse, entablar un diálogo con el pensamiento heideggeriano que, si bien ha sido fructífero, puede y debe ser matizado para conseguir enriquecer tanto a la filosofía de la imagen como a la narrativa audiovisual.

La aproximación entre análisis fílmico y el pensamiento de Heidegger ha sido, desde sus orígenes, sobradamente cauta a la hora de aceptar los límites impuestos por la teoría posterior a la Kehre. En líneas generales, una gran parte de los estudios optan por una suerte de exploración sobre la hipotética "traducción" que diversos aspectos del pensar de Heidegger han sufrido en diferentes representaciones cinematográficas. Así, hay análisis que giran en torno a la temporeidad (Zeitlichkeit) o a la angustia en diferentes filmografías (Rodríguez Serrano, 2015a, 2016), sobre las relaciones entre el expresionismo alemán y la construcción de la ciudad en el proyecto arquitectónico heideggeriano (Arenas, 2007, 2011), o incluso, sobre la manera en la que destacados "heideggerianos" - muy especialmente, Terrence Malick - han cristalizado en imágenes algunos aspectos relacionados con la naturaleza o la técnica (Fusternau y MacAvoyLeslie, 2007; Vidal Estévez, 2015).

Desde el aspecto de una teoría fílmica "pura", las relaciones con Heidegger han sido mucho más discretas. Generalmente, se ha utilizado de manera parcial, como apoyo o argumento de autoridad capaz de reforzar aspectos puntuales de índole ontológica (Palao Errando, 2004), o incluso se ha llegado a negar de manera virulenta cualquier posibilidad de compatibilidad con una correcta lectura de las imágenes (Gobantes y González Requena, 2014), o con cualquier otro tipo de cruce con otras disciplinas estéticas, sociológicas o de cualquier otra índole ajenas a la más estricta ontología existencial (Leyte, 2005). De ahí que nuestra presente investigación deje a un lado tanto la aplicación del sistema poético de Germania a un texto fílmico concreto y apueste por un análisis detenido de los rasgos de lo poemático y de sus relaciones con la imagen 
como condición previa para entender cómo y de qué manera puede el cine desvelar, ser poema y, por supuesto, ayudarnos a recuperar la urgencia de la pregunta por el Ser.

Para ello, desbrozaremos el recorrido del artículo en tres grandes secciones: En la primera —Delimitar el poema-, acudiremos directamente al seminario sobre Germania para intentar detectar lo que Heidegger entendió como la función de lo poemático, intentando extraer aquellos conceptos especialmente relevantes. Dedicaremos un tiempo a clarificar la función de la Patria (Heimat) y su labor en la construcción de comunidades histórico-destinales. En la segunda sección — La posibilidad de un poema cinematográfico-, veremos cómo puede aplicarse el concepto de lo poemático al cine, utilizando para ello no tanto las habituales teorías surgidas al hilo de la semiótica fílmica, sino desde la propia escritura heideggeriana y las indicaciones dictadas en Germania. Utilizaremos el cine de James Benning como ejemplo y detectaremos cuáles son los rasgos principales que acercan y alejan la filosofía del arte heideggeriana de lo cinematográfico. Por último, en la Propuesta final, intentaremos pensar desde dónde puede la narrativa audiovisual hoy seguir pensando junto a Heidegger siendo consciente, eso sí, de dónde y por qué se traiciona su pensamiento.

\section{DELIMITAR EL POEMA}

Para el lector que desconozca los primeros estudios de Heidegger a propósito de la obra de Hölderlin puede resultar extravagante que se hayan comparado estos textos seminales con diferentes teorías de la literatura, y en el límite, con el formalismo ruso (Warley, 2010: 209). En su seminario sobre Germania, y muy especialmente en el capítulo primero de la primera parte (Meditación preparatoria: poesía y lenguaje), Heidegger realizará un esfuerzo de síntesis para plantear una suerte de metodología de análisis poético desde su pensamiento filosófico que procederá a aplicar, con diferente rigor y diferente intensidad, en el resto de capítulos que componen 
la obra. Sin embargo, el filósofo no está tan interesado en ofrecer una suerte de "guía de análisis o de lectura" como de desbrozar aquello que podía ser lo esencialmente poemático, aquello en lo que reside la fuerza, el sentido y la verdad del poema. En el presente apartado intentaremos señalar y aclarar algunos rasgos básicos para poder, posteriormente, preguntarnos por el lenguaje audiovisual.

\subsection{La función del poema: El problema de la Patria (Heimat)}

Heidegger comienza señalando en su texto que todo poema está construido en torno a un doble movimiento (2010: 21). En primer lugar, el poema arroja al lector a una suerte de encuentro, de choque contra sí mismo, una suerte de toma de consciencia con su esencia más propia. En segundo lugar, esta toma de conciencia le hace emerger al encuentro de una comunidad originaria. Se trata de una basculación que se repetirá, con variaciones, a lo largo de todo el texto. El poema no es un entretenimiento que sirva a ningún tipo de sensibilidad subjetiva - expresión que, por lo demás, parece tener poco sentido en la reflexión heideggeriana-, ni tampoco responde a una sensibilidad creadora y romántica capaz de hacer emerger de su interior una suerte de trauma estetizado o embellecido por su sensibilidad y su dominio de las herramientas formales. El filósofo dedica todo un parágrafo $(\S 4 a)$ a cargar contra las teorías románticas de la creación y la recepción poética, intentando demostrar que el poema no es únicamente un juguete para almas sensibles sino, muy al contrario, que exige ese segundo tiempo en el que conforma comunidades, genera nexos entre los seres humanos y les sitúa en una coordenada histórico-destinal; lo que en la lúcida interpretación de Lacoue-Labarthe sería la esfera del mito (Sage), la sacralidad perdida capaz de dotar de sentido a lo humano (Lacoue-Labarthe, 2007).

Como seguramente habrá detectado el lector, aquí se encuentra el núcleo de las interpretaciones anti-heideggerianas más simples, y por extensión, de uno de los errores más habituales en la comprensión de 
su filosofía del arte. Sin duda, por tratarse de un seminario impartido en pleno auge nacionalsocialista, resulta inevitable realizar una trasposición acelerada de términos — máxime cuando el poema trabajado es nada menos que Germania - y concluir que esa comunidad histórico-destinal es la unión de los alemanes bajo el destino del III Reich. La definición de esa comunidad originaria (Gemeinschaft) se convierte, sin más, en la Alemania nazi, y su defensa del destino, en una suerte de Blut und Boden acelerada. De la misma manera que el tristemente célebre parágrafo 73 de Ser y tiempo ha sido posteriormente citado en incontables ocasiones como una suerte de celebración avant la lettre del nazismo - y ha necesitado, por cierto, de profundos y rigurosos estudios hermenéuticos para clarificar sus resonancias y su complejidad (De Beistegui, 2013)—, es necesario matizar cómo la Germania de Heidegger se vale a la vez de una resonancia lingüística indudablemente deudora de su tiempo, pero a la vez, apunta en direcciones que nada tienen que ver con el proyecto hitleriano.

En primer lugar, una lectura atenta del seminario de Germania demuestra que Heidegger en ningún momento está asimilando el concepto de Patria (Heimat) con los dogmas raciales o genéticos de la Alemania nazi ni con su justificación filosófica (Forti, 2006). Merece la pena rastrear algunos indicios que soporten esta hipótesis. Para Heidegger, la patria no es "mero lugar de nacimiento, ni paisaje familiar" (p. 87), la patria "no es un mero espacio jalonado por fronteras externas, un área natural, una localidad como escenario posible para que se represente esto o aquello" (p. 99). La patria tampoco es un "mero sitio de usufructo y explotación" (p. 100). Se nos ha hecho notar una importante matización que debe señalarse por lo que respecta al establecimiento de Heidegger de una distinción conceptual entre dos términos que no pueden ser tomados como sinónimos: de un lado Vaterland (que, en relación con la patria de los padres, puede ofrecer con mayor exactitud un marco geográfico) y Heimat, que tiene implicaciones sobre aquello que puede ser "hogareño".

Esta caracterización negativa de la patria (Vaterland) nos permite extraer alguna serie de rasgos fundamentales para realizar una correcta 
comprensión del texto: la Heimat no viene dada ni por el nacimiento ni por la extensión geográfica, es decir, no puede contraponerse con el Volk nacionalsocialista. No es una entidad política; de hecho, como ya hemos señalado, Heidegger despreciaba profundamente a gran parte de la cúpula nazi, no por razones humanitarias sino, muy al contrario, por la constante sensación de no ser lo suficientemente valorado por el engranaje cultural hitleriano. La patria, además, no puede responder a proyectos de expansión bélica como el homicida Lebensraum, con su desquiciada búsqueda de "espacio vital" a costa del exterminio sistemático de otros individuos (Dwork y Jan van Pelt, 2002), ni a proyectos de generación indiscriminada de individuos mediante un estricto control genético en estrategias de diseño socio-racial como la Lebensborn; estrategias ambas que, por otra parte, formarían parte de esa dominación brutal e indiscriminada del mundo que Heidegger denunciaría sistemáticamente en los años venideros.

Luego, si no puede trasponerse con tanta facilidad como parece a la identidad nacionalsocialista, ¿dónde estaría el anclaje de la Gemeinschaft? Para responder a esta cuestión —y depurar, por tanto, cuál es el efecto de lo poético- es necesario realizar un doble movimiento que conecte tanto al Heidegger de Ser y tiempo con los textos sobre arquitectura y habitabilidad posteriores al seminario de Germania. En efecto, otro de los rasgos que demuestran que la Kehre no fue un giro tan radical como las lecturas simplistas anuncian, es precisamente la lucha continuada que el filósofo mantuvo entre el concepto de la Heimat, el célebre heimelig/ unheimlich y toda la teoría sobre el habitar (wohnen) durante la década de los cincuenta. Si regresamos al seminario de Germania, podemos leer:

Precisamente la muerte, la que cada hombre individual debe morir por sí, aísla extremadamente en sí a cada individuo; precisamente la muerte y el aprontarse a su sacrificio crea, antes que nada, el espacio de la comunidad desde el cual surge la camaradería. La camaradería, ¿surge pues de la angustia? No y sí. No, cuando, como el pequeño burgués, se entiende por 
angustia sólo el desvalido estremecimiento de una demencial cobardía. Sí, cuando la angustia es concebida como la cercanía metafisica a lo incondicionado, que otorga una autonomía y disponibilidad supremas (Heidegger, 2010: 74).

En el clarificador parágrafo $\S 7 \mathrm{~g}$, Heidegger toma como referencia la idea de la camaradería entre los soldados ante la muerte como cimiento sobre el que edificar la idea de la Gemeinschaft. Sin embargo, no se trata de una suerte de épica militar — no les une ni la nostalgia por sus familiares ni un "entusiasmo colectivo previamente concertado" (Heidegger, 2010: 73 __, sino más bien una suerte de reinterpretación del cuidado (Sorge) basada en la aceptación épica del destino histórico individual. Lo que genera la angustia concreta, la angustia de la que surge la Heimat y el sentido que une a los individuos es, literalmente, el descubrimiento de la nadidad (Nichtigkeit), el nexo paradójico entre saber que nadie puede hacerse cargo de mi muerte individual - filosofema central en Ser y tiempo - y, a la vez, ese doblez autonomía/disponibilidad en el que se encara la Historia.

Podría tratarse de un ejercicio vacuo de retórica militar especialmente barroca si no tuviéramos en cuenta, como señalábamos anteriormente, que esta misma idea tiene antecedentes y consecuentes fundamentales en el pensamiento de Heidegger. El primero de ellos está esbozado en sus conferencias de 1924 (Heidegger, 1999a), y alcanzará su cima definitiva en el parágrafo sobre la angustia de Ser y tiempo. Se trata de la conexión entre la angustia y la tierra mediante la célebre afirmación de ese "no-estar-en-casa" (Nicht-Zuhause-sein) que por extensión, "debe ser concebido ontológico-existencialmente como el fenómeno más originario" (Heidegger, 2009, 207-208). Heidegger utilizará, concretamente, el término Unheimlichkeit, que más allá de sus referencias freudianas, apunta aquí a un estado inevitable del Dasein en el que tomamos consciencia de que el mundo — en un sentido ontológico - no sólo no puede servirnos 
como hogar, sino que además, sitúa de manera irremediable el horizonte de la muerte frente a nosotros.

En Germania, este filosofema se repite constantemente con distintas formulaciones al hilo de la obra de Hölderlin. Heidegger diseña un mundo en el que los habitantes, aislados en sus cumbres, esperan pacientemente la llegada de los dioses, intentando hacerse cargo de la angustia y del duelo que esa sensación de abandono, de no-estar-en-casa, les provoca. Debajo de todo el aparataje críptico, poético y teológico — que alcanzará su paroxismo muy especialmente en la segunda parte del seminario sobre Germania, dedicada al estudio de El Rin, con el que Heidegger sazona sus propios pensamientos-, emerge la idea de la Unheimlichkeit, y a su vez, la posibilidad de que la unión de los individuos genere esa Gemeinschaft concreta. La Gemeinschaft es el nexo, la unión en la angustia, detectada por el poeta y cristalizada en el lenguaje, del que puede surgir la Ursprache (lengua originaria).

Desde esta dirección, quizá estemos más cerca de comprender el célebre y hermoso fragmento de su Carta sobre el humanismo: "El lenguaje es la casa del Ser. En su vivienda mora el hombre. Los pensadores y los poetas son los vigilantes de esa vivienda" (Heidegger, 2000: 11).

Esta misma idea, con algunas variaciones, había emergido en otro de sus más célebres textos nacionalistas también de 1934 — ¿Por qué permanecemos en la provincia? (Heidegger, 1963) — y servirá como espina dorsal de sus estudios sobre habitabilidad y arquitectura en las décadas posteriores (Sharr, 2007, 2015). Las conexiones entre comunidad, lenguaje y hogar como tres elementos que debemos integrar en oposición a la angustia se encuentran tanto en el corazón de sus textos más focalizados sobre la teoría de lenguaje (Heidegger, 1990, concretamente en su reflexión sobre el dintel), como en aquellos en los que se teoriza la célebre cuaternidad-el cielo, la tierra, los mortales y los divinos- en la que vuelven a repetirse las ideas del tiempo de la espera, la correcta guía hacia la muerte, el respeto por la posibilidad de un espacio sagrado y la importancia del lenguaje (Heidegger, 1994). No es de extrañar, por cierto, que uno de estos textos 
estuviera encabezado con un verso del propio Hölderlin: "Poéticamente habita el hombre (...dichterisch wohnet der Mensch...)". Queda, por tanto, explicitada la conexión entre Heimat, Gemeinschaft y Wohnen. La patria no es el paraíso nacionalsocialista racial que han querido ver sus detractores, sino la unión íntima de aquellos que, una vez descubierta la angustiosa presencia de la muerte y su nadidad (Nichtigkeit, ausencia de los dioses o Nicht-Zuhause-sein) forman una comunidad basada en el lenguaje que les permite experimentar el desarraigo en una posición destinal e histórica concreta.

Regresando, por lo tanto, al principio de Germania, ya podemos aclarar los dos tiempos de la función poética: desvelar en el Dasein concreto esa nadidad, y, posteriormente, orientarle hacia otros compañeros para forjar una Gemeinschaft que permita esperar a los dioses. Llegados a este punto, debemos dar el siguiente paso: ¿puede lo cinematográfico realizar esta función propuesta por Heidegger? ¿Se puede hablar, en este contexto conceptual concreto, de poema cinematográfico?

\section{LA POSIBILIDAD DE UN POEMA CINEMATOGRÁFICO}

Para explorar las posibles conexiones entre el poema heideggeriano y el texto cinematográfico no parece suficiente con mantenerse dentro de las teorías semióticas y semiológicas popularizadas durante los años sesenta y setenta del siglo pasado en las discusiones sobre análisis fílmico. De hecho, es imposible no apuntar la tentación de caer sin más en un ejercicio de "inconmesurabilidad filosófica" (Feyerabend, 2003; Kuhn, 1983, 2005) y acabar cerrando el presente artículo concluyendo que el concepto mismo de lenguaje no puede ser compatible entre el hipotético lenguaje cinematográfico y el lenguaje desvelador heideggeriano.

Sin embargo, antes de hacerlo, nos gustaría intentar pensar con cierta profundidad qué elementos se muestran tanto a favor como en contra de dicha posibilidad. En primer lugar, la posibilidad misma del lenguaje audiovisual ha sido ampliamente teorizada desde que André Bazin concluyó 
su célebre ontología sentenciando lapidariamente: "Por otra parte, el cine es un lenguaje" (Bazin, 2001: 30). La tensión establecida posteriormente entre los detallados sistemas de clasificación semiótico-cinematográfica de, entre otros, Metz $(2001,2002)$ o el intento de teorizar las diferencias entre un cine de poesía y un cine de prosa (Pasolini y Rohmer, 1970) fueron posteriormente desbancadas a partir de los textos críticos de Jean Mitry (1991) y, algo después, el cambio de interés en los llamados film studies a favor de un enfoque postestructuralista más cercano a los Estudios Culturales.

Para nuestro proyecto actual intentaremos partir exclusivamente de Germania para entender cómo Heidegger clasifica lo poemático y ver su posible traslación al terreno de lo cinematográfico. Para ello, compararemos los núcleos de su decir sobre lenguaje y narración y los haremos colisionar con las herramientas ya establecidas y formalizadas de la narratología fílmica.

\subsection{Los dos lenguajes}

Heidegger comienza su proyecto considerando el lenguaje poético como una suerte de superación explícita de las funciones comunicacionales tradicionales. En el parágrafo 3 de Germania acomete una precisa distinción entre el decir expresivo y comunicativo frente a un decir poético. Los dos primeros son netamente ocultadores, en el sentido en el que generan zonas de confort para los individuos, forman parte de la experiencia cotidiana y bloquean esa sensación de angustia a la que hacíamos referencia anteriormente. Resulta inevitable, al leer estas páginas, no recordar tanto la habladuría (Gerede) —entendida en su sentido peyorativo- como el Uno (das Man) de Ser y tiempo (Heidegger, 2009: 134-145, 189-190).

Ciertamente, la idea de que el cine, en el caso de ser un lenguaje, forma parte de los mecanismos de alienación y de banalización de las masas atraviesa de punta a punta la teoría crítica prácticamente desde su nacimiento. Sin embargo, es necesario señalar que dentro de la propia 
naturaleza de lo cinematográfico también hay una superación de sus funciones estrictamente expresivas y comunicativas. De igual modo Heidegger señalará lo poético como una ruptura consciente sobre las normas cotidianas del lenguaje, decenas de autores han estudiado cómo diferentes modelos audiovisuales han trascendido, modificado, subvertido o puesto en duda la base misma de la manera en la que recibimos los textos cinematográficos.

Merece la pena detenerse en este punto para desarrollarlo. En primer lugar, podemos señalar que hay una suerte de consenso por parte de los teóricos de la imagen en localizar una serie de huellas formales como lo que podríamos llamar una expresión audiovisual legible, o mejor dicho, dominada por la transparencia enunciativa y en la que, de manera más o menos explícita, se generan la gran mayoría de films, y, por extensión, la publicidad audiovisual, las series, los espacios televisivos y hasta las secuencias cinemáticas de los videojuegos (Gómez Tarín, Rubio Alcover, y Tomás Samit, 2012). Esta suerte de primer lenguaje cinematográfico ha sido teorizado como el Modo de Representación Institucional o MRI (Burch, 1987) por su dispersión hegemónica y su imposición gracias a la maquinaria norteamericana de Hollywood. Su funcionamiento, principalmente acuñado por la obra de D. W. Griffith (Marzal Felici, 1998), es tomado por la base en torno a la cual se estudian las desviaciones peculiares del resto de cinematografías (Bordwell, 1995; Bordwell, Staiger, y Thompson, 1997). No es éste el lugar de entrar en la problemática ideológica que ofrecen estas cintas, si bien, sin duda, son aquellas en las que Heidegger apreció aquel peligro de "americanismo" que tanto le molestaba.

En contraposición, aparece el segundo nivel del lenguaje cinematográfico, aquel que se considera como una desviación de esa norma reguladora y que, en lugar de optar por la transparencia enunciativa, muestra las propias huellas de su escritura y busca desvelar, en primer lugar, su propia naturaleza como texto. Nos acercamos entonces al territorio de la vanguardia y de la modernidad (Font, 2002; Losilla, 2012), pero también 
al del propio manierismo de los grandes maestros (Rubio Alcover, 2010), e incluso al descubrimiento de aquellas películas que, generadas en el seno de los grandes estudios, se construían sobre excepciones formales y temáticas que provocaban estimulantes problemas de significación (Parrondo, 2013).

La primera pregunta que nos sale al encuentro es: ¿coincide este segundo nivel de lenguaje cinematográfico con esa doble función que Heidegger adscribía al poema en Germania; recordemos, desvelar la nadidad y fundar una comunidad de lenguaje? La respuesta, por cierto, no es tan sencilla como parece. Hay una fricción teórica indudable entre los dos tiempos exigidos por Heidegger al poema que pueden, además, ser ampliamente estudiados.

El primero de ellos, referente al encuentro personal con ese texto que me muestra mi no-estar-en-casa, puede ser clarificado sin demasiada dificultad. De hecho, la gran mayoría de películas de la modernidad o de la vanguardia giran en torno a esta idea: el estar en un mundo que se encuentra en constante estado de revolución contra los marcos de sentido que pretendemos imponer sobre él. Frente al mundo ficcional autosuficiente y hermético del MRI, surge la quiebra del mecanismo fílmico (Aumont, 2016) que muestra, al contrario, las costuras y la falta de fundamentación. En su proyecto influye más bien un programa en un primer tiempo ideológico - la negación del modo dominante enunciativo de Hollywood y sus conexiones con el capitalismo de mercado, crítica que por lo demás el propio Heidegger suscribió en, entre otras, la metáfora de la "tenaza" de la Introducción a la metafísica (Heidegger, 2001: 42-43) y en un segundo tiempo, la necesidad de replantear el lugar del Dasein en el mundo.

Dicho con mayor claridad: el cine poético, tal y cómo lo estamos planteando aquí, es aquel que utiliza la imagen más allá de los marcos del lenguaje cinematográfico convencional y que recupera, en sus imágenes, el problema de la mostración del mundo. Intentaremos ofrecer, al menos, un ejemplo que clarifique esta idea y que es, por lo demás, absolutamente 
coherente con la filosofía del arte heideggeriana. Nos referimos a la obra del documentalista experimental James Benning. Si tomamos como ejemplo dos propuestas como 13 lakes (2004) o 10 skies (2004), podemos observar cómo prescinde prácticamente de todos los anclajes propios del MRI: no hay causalidad narrativa, ni sutura enunciativa, ni una lógica formal que garantice el sentido del mundo. Muy al contrario, lo que se plantea es una sucesión de planos fijos, estáticos, en los que Benning ofrece recortes del mundo para su contemplación. Son imágenes en un sentido casi puro del término, representaciones autónomas que invitan al diálogo con el problema mismo de la habitabilidad del mundo, sus márgenes, sus implicaciones, que encaran la manera en la que el fluir del tiempo tiene que ver con la percepción de lo real y que, en definitiva, comparten una sensibilidad innegable con los textos de Hölderlin y con la lectura concreta de Germania. Benning, como ya han citado diferentes autores (Klimek, 2014; Pick y Narraway, 2013) subvierte las expectativas de un espectador habituado a las coordenadas de tiempo, espacio y narración para generar, en el interior de la obra, un tiempo espectatorial nuevo.

Este tiempo parte de una decisión enunciativa concreta, de una filosofía del arte rigurosa. Benning utiliza cada plano individual para observar, sin modificar ni intervenir de ninguna manera, la manera en la que la naturaleza impone su fluir. Limitado por la propia duración que le impone técnicamente la cámara y el celuloide con el que trabaja -rollos de cuatrocientos pies en 16 milímetros-, sin música ni sonidos extradiegéticos, sin figuras más allá del llamado meganarrador (García Catalán y Sorolla, 2014), Benning expone la tensión entre el lenguaje cinematográfico orientado a expresar y comunicar frente a una escritura visual que se asemeja mucho más al programa heideggeriano.

\subsection{El problema principal: El cine frente a la Ursprache}

Llegados a este punto, es el momento de preguntarse hasta qué punto la obra de Benning puede cumplir con el segundo punto de la 
función poética esbozada en Germania, esto es, la hipotética creación de comunidades originarias histórico-destinales. Y, aquí, resulta inevitable toparse frente a frente con el gran problema de nuestra investigación: la no correspondencia entre el lenguaje mítico de Heidegger (oral y escrito), y la concreción y universalidad de la expresión cinematográfica.

Desarrollemos esta idea. En cierto sentido, Heidegger confía en que se puede rastrear en cada lengua un componente que ancla sus raíces en la tradición, en el pasado, en el "tiempo de los dioses", y que puede ser traído hasta nosotros como condición para la aperturidad del Ser. Como él mismo repetirá sistemáticamente, no se trata de que el lenguaje mítico nos permita "repetir" o "traer de nuevo" — en un sentido más cercano al que proponía, pongamos por caso, Mircea Elíade (2000) — aquel tiempo perdido, sino antes bien, que nos haga conscientes del hecho mismo de la espera, de la pérdida, de nuestra relación inevitable y constante con el ocultamiento del Ser. La palabra, usada de manera poética, porta en sí misma un eco de ese tiempo; recordemos, al hilo de esto, los constantes juegos etimológicos que solían acompañar al pensamiento del filósofo, que, ayudando a la tarea del pensar, permiten poner en marcha la función de la obra de arte.

Por el contrario, la imagen audiovisual no puede remitir de ninguna manera a esa suerte de temblor mítico. El referente ontológico que se sitúa delante del objetivo de la cámara - los cielos y los lagos de Benning, pongamos por caso- coinciden puntualmente con aquello que se reproduce en el momento de la proyección, si bien, procesos técnicos como el etalonaje o la introducción de efectos digitales suelen modificar aquello que recibe el espectador. En el límite, la propia selección de la mirada que impone la angulación de la cámara, el corte o sección del mundo que se establece dentro del encuadre, o sus relaciones inmediatas con otros planos mediante el montaje, están generando efectos sobre la psicología del espectador. La vieja idea de la objetividad de la imagen (Nichols, 1997) hace ya mucho que fue superada, y muy al contrario, el debate ahora pasa por saber de las tensiones que se establecen en los 
propios procesos de creación de imágenes (Quintana, 2011).

Esto no quiere decir, sin embargo, que ciertas imágenes no hayan generado comunidades de gusto, o unión entre diversos espectadores que han creído encontrar en ciertas escrituras poéticas cinematográficas una suerte de conexión, de nexo, de camaradería ante la angustia. Muy al contrario, el trabajo de la llamada "Nueva Cinefilia" (Rodríguez Serrano, 2015b; Rosenbaum, 2010; Rosenbaum y Martin, 2011) ha consistido, precisamente, en utilizar las nuevas tecnologías para generar redes de difusión, exhibición, comentario y análisis de nuevas expresiones cinematográficas globales en comunidades abiertas. El salto hacia la globalidad y la internacionalidad ha podido tener lugar precisamente gracias a que el cine no puede ser una Ursprache, no se puede considerar un "lenguaje originario" ni siquiera en lo que respecta a ese sistema de mostración normativo, central, MRI, al que hacíamos referencia en el epígrafe anterior.

Dicho con otras palabras y con mayor claridad: los textos poéticos cinematográficos no pueden aspirar con claridad a las funciones del lenguaje en Heiegger, precisamente porque emergen de contextos ya tecnificados donde la noción de Heimat, tal y cómo la desarrollábamos en el epígrafe anterior, ya no se reduce únicamente a una nostálgica espera de los dioses y a una configuración de la tierra como algo cuyo ritmo interno y su exigencia de lentitud, calma y autogestión debe ser salvaguardado. La paradoja que nos sale al paso es que las piezas audiovisuales de Benning, con su particular anhelo de una nueva disposición ordenada de lo temporal, se distribuyen en tiempo real a cualquier lugar del mundo y en cualquier momento, de manera instantánea, desde el momento en el que son como ocurre mientras redacto estas líneas - alojadas en los servidores de Youtube.

Con lo que, definitivamente, podemos acotar el gran problema que nos impide realizar una filosofía del arte heideggeriana concreta hacia el audiovisual. La imagen fílmica, precisamente por la universalidad que impone en el uso de referentes y por las impresionantes capacidades 
de distribución global que ha generado en los últimos años, limita profundamente la creencia en esa segunda función de lo poético que el filósofo planteó en Germania. De intentar avanzar en esta dirección, únicamente podríamos concluir que el cine sirve para desvelar ese noestar-en-casa, pero que sus efectos a la hora de unir, coordinar y formar espacios de encuentro entre diferentes hombres y mujeres se entiende ahora de manera global, y en torno a factores sociológicos que nos resultan directamente incompatibles con gran parte de la propuesta heideggeriana de la Ursprache. Ciertamente, esa sensación de "sentirse como en casa" sugerida en la Heimat de Heidegger no puede ser un "espacio global" en el que todos los ciudadanos pueden tomar consciencia, al margen de sus rasgos comunitarios iniciales y de sus contextos históricos previos determinados, de los problemas derivados de su propia existencia.

Como vemos, hemos llegado al centro de la paradoja: ¿debemos negar, por tanto, al arte cinematográfico su capacidad poética? ¿Pierden sentido las piezas audiovisuales de Benning, de Terrence Malick, de Pier Paolo Pasolini, en su constante reflexión sobre el Ser, sobre el propio lenguaje cinematográfico? ¿O quizá debemos prescindir definitivamente del Heidegger posterior a la Kehre en relación al lenguaje fílmico y seguir buscando, desde otra perspectiva metodológica, cómo las películas dialogan en sordina con éste o aquel problema concreto de su pensamiento?

\section{PROPUESTA FINAL: TRAICIONAR A HEIDEGGER PARA VALERNOS DE SU PENSAR}

Como hemos desarrollado en las páginas anteriores, la filosofía del arte de Heidegger nunca se sintió cómodo trabajando con las imágenes. Como es bien sabido, el análisis del cuadro Un par de zapatos de Vincent van Gogh estaba cuajado de imprecisiones. Esto no quiere decir, sin embargo, que pudiera borrarlas por completo de su sistema de pensamiento, ni de que las exiliara de su construcción concreta de lo poético. Ya en sus seminarios de 1925 en Marburgo se puede rastrear una cierta resistencia 
frente a la visión como modo de conocimiento (Heidegger, 2004: 54), que se repetirá, posteriormente, una y otra vez, en los Cuadernos negros. Esto, sumado a la imposibilidad de combinar su defensa de la Ursprache con la propia naturaleza de lo cinematográfico, sería sin duda suficiente para concluir que sus aportaciones a la filosofía del arte no son compatibles con la práctica del análisis fílmico.

Sin embargo, no es menos cierto que una parte notable del cine poético de las últimas décadas, una vez demolido el espejismo mítico del sistema clásico de Hollywood, ha intentado hacerse cargo de esa "ausencia de los dioses", de esa falta de fundamentación, e incluso en el límite, de ese sentimiento de incredulidad que atraviesa al ciudadano contemporáneo que, tal y cómo Heidegger predijo, se encuentra dominado por procesos de tecnificación y automatización (Stiegler, 2004) que han impuesto sus tiempos —en el límite, el tiempo del mercado- por encima de cualquier relación que podamos establecer con la tierra que nos cobija, el cielo que nos resguarda, los mortales que nos acompañan en el viaje y, por supuesto, los dioses que no se manifiestan.

Al observar, pongamos por caso, los paisajes arrasados de Andrei Tarkovsky o la angustia que atraviesa a los personajes de Antonioni, resulta imposible alejar, sin más, la posibilidad de que las herramientas de Heidegger entren en diálogo con aquellas cintas. Emergen de una preocupación paralela y responden —o quizá, ensayan una respuesta-, si bien mediante sensibilidades distintas, al problema fundamental del Ser. Luego es necesario aceptar que debemos arrebatar al propio Heidegger los límites de su filosofía del arte para ayudarnos, gracias a él, a pensar lo que él mismo no quiso ni supo pensar.

Ciertamente, es un planteamiento que, desde una ortodoxia estricta, resulta insostenible. Como el lector ya habrá comprobado, para el estricto guardián del pensamiento heideggeriano, el cine permanecerá siempre sometido a la técnica y a los procesos de ocultamiento del mundo. Sin embargo, para aquellos que deseen abandonar esta idea, nos gustaría señalar un último elemento en Germania que permite hermanar, de alguna 
manera, la propia búsqueda heideggeriana con los estudios de narratología fílmica. Se trata del parágrafo 5 en su totalidad, titulado La pregunta por el "Nosotros" en el torbellino del diálogo. Contra todo pronóstico, este parágrafo es lo más cerca que estuvo Heidegger de plantear un sistema completo y sistemático de análisis textual.

El parágrafo 5 está dividido, a su vez, en cinco fragmentos. Más allá de la aplicación concreta al poema de Hölderlin, lo que Heidegger teoriza es un acercamiento al poema desde tres ejes: el punto de vista ( $\$ 5 \mathrm{a}, \S 5 \mathrm{~b}$ y $§ 5 \mathrm{c})$, el lugar y el tiempo desde el que se enuncia el poema y en el que se sitúa la acción ( $\$ 5 \mathrm{~d})$ y, por último, el propio espacio que el poema dedica al hipotético receptor; lo que, en términos semióticos, estaríamos tentados a denominar, con todas las reservas y precauciones, una suerte de enunciatario (§5e). A su vez, el parágrafo 6 retomará algunas ideas del $\S 5 \mathrm{~d}$ con respecto al tiempo de la narración para poder introducir el concepto capital del Acontecimiento (Ereignis), si bien, nosotros tendremos que dejar fuera este aspecto en el presente texto.

El sistema de Heidegger es, en esencia, el mismo que se lleva décadas planteando la narratología fílmica (Gómez Tarín, 2011; Jost y Gaudreault, 1995). Los pasos que el filósofo plantea para rastrear la manera en la que un texto concreto se enfrenta con la pregunta por el Ser son los mismos que guían el análisis fílmico: ¿Quién nos habla? ¿Desde qué tiempo? ¿Cómo se relacionan el tiempo interno del texto con el tiempo externo del espectador? Y muy especialmente, ¿cómo responde el texto a la pregunta clave Quiénes somos nosotros? La brillante diferencia que aporta la lectura y la guía de Heidegger es que su filosofía del arte no pretende simplemente hacer un ejercicio estructuralista que pretenda reducir, con mayor o menor precisión y riqueza, el texto a una serie de parámetros objetivables de emisión y lectura. Más allá, lo que pretende es que dichas preguntas guíen nuestra reflexión fuera del texto mismo, no en la dirección del poema, sino en la dirección mayúscula de la pregunta por el Ser. El conocimiento de un texto — un poema de Hölderlin, un film de Tarkovsky — ya no se agota en sí mismo ni se convierte en un mero ejercicio de academicismo vacío. 
Muy al contrario, emerge más allá de los límites de la gramática o de la lingüística cinematográfica y se convierte en un pensar filosófico, esto es, poético, en el que podemos recuperar ese Denken que no se conforma en los datos estadísticos — tan de moda en el panorama contemporáneo de las ciencias sociales, y tan valorado por las Agencias de Calidad-, sino que consigue llegar más lejos que los simples indicadores numéricos a los que se dota automáticamente de un cierto valor de verdad.

Antes de concluir, nos gustaría añadir una breve matización de lo expuesto hasta el momento. Sin duda, una lectura crítica puede acusar, y no sin razón, a nuestra propuesta final de apoyarse demasiado en los parámetros narratológicos. El cine $-\mathrm{y}$ el caso mencionado de Benning es un buen ejemplo_-, propone una serie de complejidades formales derivadas de la propia naturaleza de la imagen, de la percepción de lo visual y de decenas de factores que escapan más allá de un enfoque que, como advertimos al comienzo del texto, peca irremediablemente de logocéntrico y, quizá, de endeudarse demasiado en las herencias de las teorías literarias. Abrir nuestra reflexión a estos campos es una labor de futuro, que esperamos poder continuar en los próximos años. Sin duda, un análisis formal exhaustivo de textos cinematográficos poéticos es capaz de ofrecer grandes resultados; véase, por ejemplo, el estudio propuesto en Bordwell, 1981 a partir de los films de Carl Th. Dreyer. Sin embargo, y como hemos defendido en el presente artículo, la recuperación de la herencia heideggeriana es necesaria para no olvidar que en el centro mismo de la poesía (y del cine poético tal y cómo lo hemos delimitado) se encuentra una invitación — quizá, una obligación - a filosofar, esto es, a salir al encuentro del Ser, incluso a riesgo de extraviarse. 


\section{REFERENCIAS BIBLIOGRÁFICAS}

ARENAS, L. (2007). "El último expresionista". En Cultura contra civilización. En torno a Wittgenstein, N. Sánchez Durá (ed.), 81-102. Valencia: Pre-Textos.

(2011). Fantasmas de la vida moderna. Ampliaciones y quiebras de lo subjetivo en la ciudad contemporánea. Madrid: Trotta.

AUMONT, J. (2016). Límites de la ficción. Consideraciones actuales sobre el estado del cine. Santander: Shangrila.

BAZIN, A. (2001). ¿Qué es el cine? Madrid: Rialp.

BORDWELL, D. (1981). The films of Carl-Theodor Dreyer. Berkeley: University of California Press.

(1995). El significado del filme: inferencia y retórica en la interpretación cinematográfica. Barcelona: Paidós.

BORDWELL, D.; STAIGER, J. y THOMPSON, K. (1997). El cine clásico de Hollywood : estilo cinematográfico y modo de producción hasta 1960. México: Paidós.

BURCH, N. (1987). El tragaluz del infinito: contribución a la geneaología del lenguaje cinematográfico. Madrid : Cátedra.

DE BEISTEGUI, M. (2013). Heidegger y lo político. Buenos Aires: Prometeo Libros.

DWORK, D. y JAN VAN PELT, R. (2002). Auschwitz. New York: W. W. Norton \& Company.

ELIADE, M. (2000). El mito del eterno retorno : arquetipos y repetición. Madrid: Alianza Editorial.

FARÍAS, V. (2009). Heidegger y el nazismo. Mallorca: Objeto perdido.

FAYE, E. (2009). Heidegger: la introducción del nazismo en la filosofía (En torno a los seminarios inéditos de 1933-1935). Madrid: Akal.

FEYERABEND, P. K. (2003). Contra el método. Barcelona: Folio.

FONT, D. (2002). Paisajes de la modernidad. Cine europeo, 1960-1980. Barcelona: Paidós.

FORTI, S. (2006). "The Biopolitics of Souls: Racism, Nazism, and Plato". 
Political Theory 34.1, 9-32.

FUSTERNAU, M. \& MACAVOYLESLIE. (2007). “Terrence Malick's Heideggerian Cinema: War and the Question of Being in The Thin Red Line". En The Cinema of Terrence Malick, H. Patterson (ed.), 26-37. London: Wallflower.

GARCÍA CATALÁN, S. y SOROLLA, T. (2014). "Morfologías de nuestros áridos días felices". L'Atalante. Revista de Estudios Cinematográficos 17, 46-52.

GOBANTES, M. y GONZÁLEZ REQUENA, J. (2014). El texto y el abismo. Diálogos con González Requena. Barcelona: Sans Soleil.

GÓMEZ TARÍN, F. J. (2011). Elementos de narrativa audiovisual: expresión y narración. Santander: Shangrila.

GÓMEZ TARÍN, F. J.; RUBIO ALCOVER, A. y TOMÁS SAMIT, A. (2012). "Punto de vista y videojuegos. Un acercamiento multidisciplinar". En Actas del IV Congreso Internacional Latina de Comunicación, 1-22. La Laguna: Congreso Latina de Comunicación. HEIDEGGER, M. (1958). Arte y poesía. México: Fondo de Cultura Económica.

(1963). “¿Por qué permanecemos en la provincia?” Eco 6.5, 472476.

(1989). La autoafirmación de la Universidad alemana; El Rectorado, 1933-1934 ; Entrevista del Spiegel. Madrid: Tecnos.

(1990). De camino al habla. Barcelona: Ediciones del Serbal.

(1994). “Construir, habitar, pensar". En Conferencias y artículos, M. Heidegger, 127-142. Barcelona: Ediciones del Serbal. (1995). Caminos de bosque. Madrid: Alianza Editorial. (1999a). El concepto de tiempo. Madrid: Trotta. (1999b). Hölderlins Hymnen "Germanien" und "Der Rhein". Frankfurt: Vittorio Klostermann. (2000). Carta sobre el humanismo. Madrid: Alianza Editorial. (2001). Introducción a la metafísica. Barcelona: Gedisa. (2004). Lógica: La pregunta por la verdad. Madrid: Alianza. 
(2009). Ser y tiempo. Madrid: Trotta.

(2010). Los himnos de Hölderlin "Germania” y "El Rin." Buenos Aires: Editorial Biblos.

(2015). Cuadernos negros (1931-1938). Madrid: Trotta.

JOST, A. y GAUDREAULT, F. (1995). El relato cinematográfico: Ciencia y narratologia. Barcelona: Paidós.

KANT, I. (2007). Crítica del juicio. Madrid: Austral.

KLIMEK, R. (2014). "How the Light Gets In: Notes on James Benning's Ten Skies". Raritan Quarterly 159, 1-10.

KOCKELMANS, J. J. (1972). On Heidegger and Language. Evanston:

Northwestern University Press.

KUHN, T. S. (1983). La tensión esencial. Madrid: FCE.

(2005). La estructura de las revoluciones cientificas. Madrid: FCE.

LACOUE-LABARTHE, P. (2007). Heidegger. La política del poema. Madrid: Trotta.

LEYTE, A. (2005). Heidegger. Madrid: Alianza Editorial.

LOSILLA, C. (2012). La invención de la modernidad o cómo acabar de una vez por todas con la historia del cine. Madrid: Cátedra.

MANSBACH, A. (2002). Beyond subjectivism : Heidegger on language and the human being. London: Greenwood Press.

MARZAL FELICI, J. (1998). David Wark Griffith. Madrid: Cátedra.

METZ, C. (2001). El significante imaginario: psicoanálisis y cine. Barcelona: Paidós.

(2002). Ensayos sobre la significación en el cine. Barcelona: Paidós.

MITRY, J. (1991). La semiología en tela de juicio (cine y lenguaje).

Madrid: Akal.

MOELLER, F. (2001). The Film Minister - Goebbels and the Cinema in the "Third Reich". California: Edition Alex Menges.

MOLINUEVO, J. L. (1998). El espacio politico del arte: arte e historia en Heidegger. Madrid: Tecnos.

NICHOLS, B. (1997). La representación de la realidad: cuestiones y conceptos sobre el documental. Barcelona: Paidós. 
PALAO ERRANDO, J. A. (2004). La Profecía de la imagen-mundo: para una genealogía del paradigma informativo. Valencia: Ediciones de la Filmoteca / Instituto Valenciano de Cinematografia Ricardo Muñoz Suay.

PARRONDO, E. (2013). "Muerte y vida en el western: La diligencia (Stagecoach, John Ford, 1939)". Trama \& Fondo: Revista de Cultura 35, 127-144.

PASOLINI, P. P. y ROHMER, E. (1970). Cine de poesía contra cine de prosa. Barcelona: Anagrama.

PAUL JANZ, C. (1988). Friedrich Nietzsche. 1. Infancia y juventud. Madrid: Alianza Editorial.

PICK, A. y NARRAWAY, G. (2013). Screening nature: Cinema Beyond the Human. New York: Berghahn Books.

QUESADA, J. (2008). Heidegger de camino al holocausto. Madrid: Biblioteca Nueva.

QUINTANA, À. (2011). Después del cine : imagen y realidad en la era digital. Barcelona: Acantilado.

RODRÍGUEZ, R. (2006). Heidegger y la crisis de la época moderna. Madrid: Editorial Síntesis.

RODRÍGUEZ SERRANO, A. (2015a). “Arquitecturas de la angustia: un diálogo entre Martin Heidegger y Stanley Kubrick". Trama \& Fondo: Revista de Cultura 38, 83-94.

(2015b). "La cinefilia 2.0 y el frameo: apuntes teóricos sobre el collage visual en la Nueva Crítica cinematográfica". adComunica. Revista Cientifica de Estrategias, Tendencias E Innovación En Comunicación 10, 99-113.

(2016). "Martin Heidegger en El Rincón de las Fresas Salvajes (Smultronstället, Ingmar Bergman, 1957): narrativas audiovisuales para mostrar la temporalidad”. Comunicación y Hombre 12, 273 289.

ROSEnBAUM, J. (2010). Goodbye Cinema, Hello Cinephilia: Film culture in transition. Chicago: The University of Chicago Press. 
ROSENBAUM, J. y MARTIN, A. (2011). Mutaciones del cine contemporáneo. Madrid: Errata Naturae.

RUBIO ALCOVER, A. (2010). El don de la imagen. Un concepto del cine contemporáneo. Santander: Shangrila.

SHARR, A. (2007). Heidegger for architects. Oxon: Routledge. (2015). La cabaña de Heidegger: Un espacio para pensar. Barcelona: Gustavo Gili.

SHERRAT, Y. (2014). Los filósofos de Hitler. Madrid: Cátedra.

STIEGLER, B. (2004). La técnica y el tiempo, vol. 3: El tiempo del cine y la cuestión del malestar. Gipuzkoa: Hiru.

VIDAL ESTÉVEZ, M. (2015). Theo Angelopoulos. Madrid: Cátedra.

WARLEY, J. (2010). "Martin Heidegger. Los himnos de Hölderlin Germania y El rin" Anclajes 14, 209-211.

XOLOCOTZI, Á. y TAMAYO, L. (2012). Los demonios de Heidegger: Eros y manía en el maestro de la Selva Negra. Madrid: Trotta.

Recibido el 12 de abril de 2018.

Aceptado el 17 de mayo de 2018. 